\title{
Investigating the reliability and validity of the Toddler Home Learning Environment (THLE) scale
}

\author{
James Hall ${ }^{1 *}$, Kathy Sylva ${ }^{2}$, Pamela Sammons ${ }^{2}$, Rebecca Smees ${ }^{3}$, Maria Evangelou ${ }^{2}$, \\ Teresa Smith ${ }^{4}$ and Jenny Goff ${ }^{2}$ \\ ${ }^{1}$ Southampton Education School, University of Southampton, Southampton, United Kingdom, ${ }^{2}$ Department of Education, \\ University of Oxford, Oxford, United Kingdom, ${ }^{3}$ Department of Psychology, University of Sussex, Brighton, United Kingdom, \\ ${ }^{4}$ Department of Social Policy and Intervention, University of Oxford, Oxford, United Kingdom
}

OPEN ACCESS

Edited by:

Guillermo Solano-Flores, Stanford University, United States

Reviewed by: Frank Niklas,

Ludwig Maximilian University of Munich, Germany

Gavin T. L. Brown,

The University of Auckland, New Zealand

${ }^{*}$ Correspondence: James Hall

J.E.Hall@Soton.ac.uk

Specialty section:

This article was submitted to Assessment, Testing and Applied Measurement, a section of the journal Frontiers in Education

Received: 07 July 2020 Accepted: 04 June 2021 Published: 23 June 2021

Citation: Hall J, Sylva K, Sammons P, Smees R, Evangelou M, Smith $T$ and Goff J (2021) Investigating the reliability and validity of the Toddler Home Learning

Environment (THLE) scale.

Front. Educ. 6:581005.

doi: 10.3389/feduc.2021.581005
Home learning environments prior to school are well-known predictors of educational trajectories but research has neglected children aged under three. The new Toddler Home Learning Environment (THLE) scale is one response and this paper investigates its reliability and validity. The THLE is an adaptation of the Preschool HLE (PHLE) measure developed by the Effective Pre-School Primary and Secondary Education (EPPSE) investigation in the 1990s. The THLE was developed as part of the Evaluation of Children's Centers in England (ECCE) investigation that followed a sample of 2,608 of families from 14 to 38 months. The THLE was administered at 14 months, the PHLE at 38. The 8-item THLE evidences internal consistency via statistical reliability coefficients and Confirmatory Factor Analysis plus measurement validity via statistically significant and research-appropriate associations with the PHLE, three measures of child development, and child and parent demographics. This paper moves the HLE literature forward with a new parental self-report scale of the HLE that is for use with toddlers.

Keywords: home learning environment, parent-child interaction, toddlerhood and early relationships, validity and reliability analyses, toddlers

\section{INTRODUCTION}

Informed by social-constructivist theories (e.g. Bruner 1978; Vygotsky, 1978) and ecological theories (e.g. Bronfenbrenner and Morris, 2006) of learning and child development, the Home Learning Environment (HLE) that surrounds children and young people has been subject to extensive study and measurement (see Lehrl et al., 2020). Although there is a trend to differentiate literacy and numeracy aspects of the HLE (e.g. Niklas et al., 2020), significant cross developmental domain effects are commonly found (e.g. Niklas and Schneider, 2017) and these support the continuing specification of single-scale HLE measures (especially for younger age groups). However and despite its extensive study, the international literature base on the HLE still retains systematic knowledge gaps (e.g. Silinskas et al., 2020), one of which concerns the HLE for children aged under age three years (a relatively infrequently studied period; Burghardt et al., 2020) -- a gap to which this paper responds.

Given that research on the HLE for children of any age stresses the importance of adult-child interactions (e.g. Crampton and Hall, 2017; Lehrl et al., 2020), consideration of parenting practices linked to child development in the under-threes can foster understanding of the toddler HLE. These parenting practices include (but are not limited to): 
- Shared reading activities that promote both emergent literacy skills (Rodriguez and Tamis-LeMonda, 2011) and language development via high-quality verbal interactions (Hayes and Berthelsen, 2020);

- Activities that regulate a child's arousal, distress, and sensory stimulation (eventually internalized as selfregulation; Posner et al., 2014);

- Parents (typically) acting as their child's first play partners which benefit the development of (cross-contributing) motor, cognitive, and social skills (e.g. Dinkel and Snyder, 2020).

A well-established and robust international evidence base exists (and continues to grow; e.g Melhuish et al., 2008; Bonci et al., 2011; Romeo et al., 2018) that attests to the long-term and sizable positive impacts of the HLE upon educational trajectories, educational equity, and long-term developmental outcomes (e.g. Jeynes, 2005; Son and Morrison, 2010; Sammons et al., 2015b; Shuey and Kankaras, 2018). The HLE in the preschool years is particularly important because it can have: 1. Effects on attainment through to adolescence (e.g. Cunningham and Stanovich, 1997); 2. Effects on attainment that are above and beyond those associated with social disadvantage (e.g. Flouri and Buchanan, 2004); and 3. The potential to partially attenuate the detrimental effects of social disadvantage on developmental and educational outcomes (e.g. Ramey and Ramey, 2004).

A large volume of evidence concerning the long-term impacts of the HLE -- and of the preschool HLE in particular -- comes from the Effective Pre-School, Primary and Secondary Education (EPPSE) project (see Sammons et al., 2004; Melhuish et al., 2008; Sammons et al., 2015b; Toth et al., 2020). This was a prospective nationally representative longitudinal study that took place in England between 1997 and 2014, followed a sample of 3,000+ children from mean age three years through to age 16, and was the first large-scale United Kingdom investigation to focus upon the effectiveness of early years education. While it is outside the remit of this paper to review all of EPPSE's findings (for details see Sylva et al., 2010), it is important to note that the tool developed by EPPSE to measure the HLE in the preschool years, here termed the Preschool Home Learning Environment (PHLE) scale, features in EPPSE publications that reveal long-term effects (e.g. Baker et al., 2014) and all three of the types of HLE effects documented above (e.g. Sammons et al., 2014; Sammons et al., 2015b; Toth et al., 2020). Partially because of such effects, EPPE's PHLE scale has since featured in several subsequent large-scale and high-profile prospective longitudinal studies of child development and education including the Millennium Cohort Study (MCS; Dearden et al., 2011; de la Rochebrochard, 2012) and the Study of Early Education and Development (SEED; Melhuish et al., 2017). It has also influenced the development of measures of the HLE in other countries including the BiKS longitudinal study in Germany (Anders et al., 2013; Sammons and Anders, 2015).

However, despite growing international evidence documenting the mid and longer term effects of the HLE experienced by children from age three years, much less is known about the long-term effects from the HLE experienced by very young children under age three (Dodici et al., 2003; Burghardt et al., 2020) because it has been less frequently assessed (e.g. Elardo and Bradley, 1981) as compared to those aged three years and up. While it is beyond the scope of this paper to speculate on the reasons for this neglect, it is important to recognize that this initial period of life (encompassing infancy and toddlerhood) is characterized by rapid growth and change, particularly for language development (e.g. Rodriguez and Tamis-LeMonda, 2011), and equally rapid changes in adultchild interactions and activities that are developmentally appropriate (e.g. Brophy-Herb et al., 2018). Thus, understanding the effects of the HLE experienced during the first three years of life is no less important than understanding the effects from the HLE at later ages. For quantitative research to document these effects, an assessment of the HLE for toddlers is required that demonstrates measurement validity and reliability.

This paper responds to the (comparative) gap in knowledge regarding the effects of the HLE for the under-threes by investigating the reliability and validity of a parental selfreport assessment tool (an adaption of EPPSE's PHLE) that measures the activities that take place between adults and toddlers in the homes that support their learning. A demonstrably reliable and valid measure of toddlers' HLE would help researchers, practitioners and policy makers to better understand the impacts of the activities that adults engage in with their toddlers that support their learning and enhance outcomes. In turn, this improved understanding has the potential to shape policy and practice by increasing our understanding of the drivers of child development, educational progress, and ultimately supporting greater educational equity.

The research question addressed by this paper is, Is the Toddler Home Learning Environment (THLE) scale a reliable and valid measure of the activities and resources that support children's early learning at home?

This research question was answered via statistical analysis of data from the nationally-representative Evaluation of Children's Centers in England (ECCE) project (2009-2015; details below) and through appraisal of several aspects of scale reliability and validity:

1. For a reliable THLE scale: First, a lack of homogeneity, floor, and ceiling effects in parent responses to THLE items. Second, statistically satisfactory evidence supporting the specification of a single THLE scale and the consistency of the THLE scale's items in indicating this scale (details within the below Analytic Approach Section).

2. For a valid THLE scale: Satisfactory statistical evidence of measurement validity via examination of various combinations of criterion validity (via concurrent and predictive validity) with construct validity (via convergent and discriminant validity). First, predictive convergent validity was investigated via estimation of the association between the THLE and the PHLE. Second, the concurrent (and predicted) convergent and discriminant validity of the THLE was investigated via estimation of its association with other measures taken at the baseline (toddler) assessment point of the ECCE study. Third, further evidence of 
measurement validity across both the criterion and construct domains was obtained by comparing how HLE associations with other measures changed (or remained constant) across the toddler and preschool period.

Together, these measurement validation analyses extend published ECCE findings that have already shown the THLE scale to significantly and positively predict three measures of child development during the preschool period (over and above a range of background measures including child age, gender, and health, plus family socioeconomic status; see Sammons et al., 2015a): verbal cognitive abilities, non-verbal cognitive abilities, and prosocial behavior. This latter association being particularly important because it reinforces findings elsewhere that stress the importance of the HLE for socioemotional competency (e.g. Wirth et al., 2020).

\section{MATERIALS AND METHODS}

\section{Design}

The Evaluation of Children's Centers in England (ECCE) project was a prospective longitudinal study that followed a sample of 2,608 children (and their families) from mean age 14 months to mean age 38 months-all of whom were registered users at one of 117 Sure Start Children's Centers (SSCCs; see Sylva et al., 2015). The ECCE project used a research design with five strands to meet five project objectives (one strand per objective): 1. To reveal models of SSCC leadership structure; 2 . To identify patterns in the types of services that were used by families; 3 . To identify common patterns of services offered by SSCCCs; 4 . To identify the impact of SSCCs on child, mother, and family outcomes; and 5 (based on results from Strands 1-3); 5. To identify the costeffectiveness of SSCCs (based on results from Strands 2 and 4).

Informed by the findings of previous studies carried out in the early years (particularly EPPSE, Sylva et al., 2010; and the National Evaluation of Sure Start, Belsky et al., 2006), positive changes to HLEs were one of the family outcomes upon which SSCCs were hypothesized to impact. As such, HLEs were measured at both study outset (via the ECCE developed Toddler Home Learning Environment scale; THLE) and again at mean child age 38 months (via use of the EPPSE developed PHLE scale).

\section{Sample}

There are two samples of families considered in this paper: A sample of 5,717 who took part in baseline assessments in 2012 (when their children were mean age 14 months) and a sub-sample of 2,608 who were followed up in 2014 because their SSCCs were taking part in a parallel longitudinal study (see Maisey et al., 2015). This systematic selection of families for follow-up resulted in samples with differing demographic characteristics. While the proportions of male and female children did not significantly differ between the 2,608 and the remaining 3,109 families $\left(\mathrm{X}^{2}(1\right.$, $\mathrm{n}=5,717)=2.07, p=0.151)$, nor did the mental health of mothers at baseline $(\mathrm{t}(5319.87)=1.29, p=0.196)$, this was not the case for other demographic characteristics. Instead, the longitudinal sample of 2,608 families featured significantly greater numbers of: White British families and fewer families from Pakastani and "Mixed Race" backgrounds $\left(\mathrm{X}^{2}(8, \mathrm{n}=5,708)=28.31, p<0.001\right)$, mothers who held a higher level of qualification $\left(X^{2}(6\right.$, $\mathrm{n}=5,683)=196.41, p<0.001)$, and households with higher average incomes $(\mathrm{U}=2,776,755.50, \mathrm{n}=5,199, p<0.001)$.

Because the baseline sample and longitudinal sample differed from one another on a number of demographic characteristics, the two samples were put to different purposes within this paper. The baseline data from the 5,717 families were used within statistical appraisal of the reliability of the THLE scale (Research Question 1; making use of all THLE data obtained from the 5,717 families) while the longitudinal data from the 2,608 families were used in the appraisal of measurement validity (Research Question 2) as this relied upon comparing THLE scores to PHLE scores and the PHLE scores were only sought from the 2,608. Full details on these analyses are provided in the Analytic Approach Section below.

In terms of sample to population representativeness, the ECCE project followed a sample of SSCCs that were representative of Phase 1 and 2 SSCCs in England between 2009 and 2014 (see Tanner et al., 2012) and the 2,608 families who were followed overtime were all registered users of one of these centers. The result is a sample of families who are broadly representative of those families who used Phase 1 and 2 SSCCs in England between 2012 and 2014 (Sammons et al., 2015a).

Measurement of the sampled families' PHLE was taken on average 24 months after the baseline assessments and was only carried out within the purposively selected longitudinal sample of 2,608 families. At both measurement points (mean child ages 14 and 38 months), assessments of HLE and measures describing children and families, were carried out by a trained team of fieldworkers who visited the home of each child (Maisey et al., 2013; Maisey et al., 2015). Detailed information regarding the characteristics of the sampled SSCCs is found in Goff et al. (2013), Evangelou et al. (2014) and Sylva et al. (2015), information regarding the baseline sample of children and families in Maisey et al. (2013); as can details of the project's research ethics), and full information on the longitudinal sample of children and families who participated in the impact analyses is given by Sammons et al. (2015a).

\section{Measures}

The Toddler Home Learning Environment (THLE) scale was developed by the ECCE team as an adaptation of EPPSE's PHLE scale. The THLE measure was designed to serve as a baseline assessment (at mean child age 14 months) of the various developmentally appropriate activities that toddlers took part in alongside their adult caregivers. Primary caregivers (PCGs-of whom 96\% were mothers; see Sammons et al., 2015a) selfreported the frequency with which their toddler engaged in seven of these activities in face-to-face interviews where their responses were recorded using 7-point frequency rating scales (coded 1 to 7 ). Accompanying these seven frequency questions was an extra question that asked PCGs to report the number of books in the home that were for the toddler (again using a 7-point rating scale). This non-frequency question was developed in recognition of the fact that the opportunity to engage in more frequent adult-toddler activities related to literacy acquisition is 
TABLE 1 | Wording, response options, and descriptive statistics for the eight items developed for potential inclusion in the Toddler Home Learning Environment (THLE) scale, the two items relating to toddler television watching, and the seven items included in the Preschool Home Learning Environment (PHLE) scale.

Toddler home learning environment (THLE) items

1. How often does someone at home take (child) out of the house, for example visiting family or friends, or going to the park? ( $\mathrm{n}=5,714$; Median = 6; Inter-Quartile range $[\mathrm{IQR}]=3$ )

2. How often does someone at home draw (child)'s attention to the names of things during their day-to-day activities? ( $\mathrm{n}=5,712 ;$ Median = 7; IQR = 0)

3. How often does someone use blocks or shape sorting toys with (child)? ( $n=5,710$; Median = 6; IQR = 2)

4. How often does someone at home talk about, or try to teach (child) the names of colors or shapes? $(n=5,711 ;$ Median = 6; $\mathrm{IQR}=2)$

5. How often does someone at home sing songs or nursery rhymes to or with (child)? $(\mathrm{n}=5,712 ; \mathrm{Median}=7 ; \mathrm{IQR}=1)$

6. How often does (child) get a chance to play in a messy way, for example using playdough, paints, or sand? $(n=5,710$;

Median $=2 ; \mathrm{IQR}=3$ )

7. Although (child) is very young, some children do enjoy being read to or handling books designed for babies. How often does someone at home read to (child)? ( $n=5,713$; Median = 6; IQR = 2)

8. How many books written for babies or toddlers does (child) have? ( $n=5,712$; Median = 5; $I Q R=3$ )
Parental self-report response options

1. Very rarely

2. Once a week

3. Twice a week

4. Three times a week

5. Four times a week

6. Five or six times a week

7. Every day or more than once a day

1. Never/Not yet

2. Have done this once or twice

3. Less than once a week

4. Once a week

5. Several times a week

6. Once a day

7. More than once a day

\section{Toddler television watching items}

A. How much time does the child spends watching TV/DVDs on their own while someone else is busy in the household? (n = 5,709; Median = 2; IQR = 2)

B. How much time does the child spends watching TV/DVDs together with someone at home? $(n=5,708 ;$ Median = 1; $\mathrm{IQR}=1)$
1. None

2. Fewer than 30 min per day

3. $30 \mathrm{~min}-1 \mathrm{~h}$ per day

4. 1-2 h per day

5. 2-3 h per day

6. 3-4 h per day

7. More than $4 \mathrm{~h}$ per day

\section{Preschool home learning environment (PHLE) items}

1. How often does someone at home read to (child)? $(n=2,576$; Median $=4 ; \mid \mathrm{QR}=1)$

2. How often does someone at home take (child) to the library? $(n=1,432 ;$ Median $=2 ; I Q R=1)$

\author{
1. Never \\ 2. Have done this once or twice \\ 3. Less than once a week \\ 4. Once a week \\ 5. Several times a week \\ 6. Once a day \\ 7. More than once a day \\ 1. Occasionally or less than once a week \\ 2. 1 or 2 days a week \\ 3. 3 times a week \\ 4. 4 times a week \\ 5. 5 times a week \\ 6. 6 times a week \\ 7. 7 times a week/constantly
}

IQR: Interquartile Range.

constrained by the availability of developmentally appropriate materials (Bradley and Caldwell, 1995), and that the availability of these materials will be influenced, at least in part, by household income (e.g. De Bondt et al., 2020).

During the development of the THLE, two items were devised that focused not on the THLE (on activities concerning adulttoddler interaction) but instead on toddler television watching as a kind of 'displacement activity' (e.g. Dore et al., 2020) from the interactions that promote learning. These two items were developed alongside the THLE items in order to equip the ECCE study with the ability to describe other things that toddlers may have been doing other than engaging in interactions linked to learning and development. The full text of the items developed to reflect the THLE and the items developed to capture toddler television watching (plus the response options to these items) is shown in Table $\mathbf{1}$ with descriptive statistics. Statistical results that informed the development of the THLE scale are reported in the Results. 
TABLE 2 | Descriptive statistics for the additional measures included in this study.

\begin{tabular}{|c|c|c|c|}
\hline Measure & Categories & $\mathbf{n}$ & $\%$ or mean \pm sd \\
\hline Child gender (binary; male coded high) & & 5,717 & $51.1 \%$ \\
\hline Child age at "baseline" (months) & & 5,708 & $14.12 \pm 1.76$ \\
\hline Child age at "outcome" (months) & & 2,608 & $38.14 \pm 2.82$ \\
\hline Mother age at "baseline" (years) & & 5,677 & $30.38 \pm 5.89$ \\
\hline \multirow[t]{7}{*}{ Baseline highest PCG qualification ( $n=5,683$ ) } & No qualification* & 520 & $9.1 \%$ \\
\hline & NVQ level 1 & 408 & $7.1 \%$ \\
\hline & NVQ level 2 & 1,366 & $23.9 \%$ \\
\hline & NVQ level 3 & 1,001 & $17.5 \%$ \\
\hline & NVQ level 4 & 1,541 & $27.0 \%$ \\
\hline & NVQ level 5 & 638 & $11.2 \%$ \\
\hline & "Other" & 209 & $3.7 \%$ \\
\hline \multirow[t]{5}{*}{ Baseline home tenure $(n=5,710)$} & Rent free* & 230 & $4.0 \%$ \\
\hline & Rent it & 2,737 & $47.9 \%$ \\
\hline & Shared ownership & 76 & $1.3 \%$ \\
\hline & Mortgage & 2,400 & $42.0 \%$ \\
\hline & Own it outright & 267 & $4.7 \%$ \\
\hline \multirow[t]{7}{*}{ Baseline household income ( $n=5,199)$} & $<£ 4.999$ & 191 & $3.3 \%$ \\
\hline & $£ 5.000-£ 5.999$ & 757 & $13.2 \%$ \\
\hline & $£ 10.000-£ 19.999$ & 1,198 & $21.0 \%$ \\
\hline & $£ 20.000-£ 29.999$ & 957 & $16.7 \%$ \\
\hline & $£ 30.000-£ 39.999$ & 761 & $13.3 \%$ \\
\hline & $£ 40.000-£ 49.999$ & 589 & $10.3 \%$ \\
\hline & $>£ 50,000^{*}$ & 746 & $13.0 \%$ \\
\hline Toddler PCG: mental health/well-being & & 5,330 & $22.56 \pm 5.59$ \\
\hline Toddler PCG: parenting stress ('parental distress' subscale) & & 5,455 & $26.30 \pm 8.09$ \\
\hline Preschool PCG: mental health/well-being & & 2,449 & $22.15 \pm 4.98$ \\
\hline Preschool PCG: parenting stress ("parental distress" subscale) & & 2,553 & $25.86 \pm 7.75$ \\
\hline
\end{tabular}

sd, standard deviation; *Reference category when the measure was subsequently represented with dummy-coded binary measures; sd, standard deviation; PCG, Primary Caregiver; $N V Q$, National Vocational Qualification.

The Preschool Home Learning Environment (PHLE) scale is the same (primary caregiver reported) measure of HLE originally developed by the EPPSE project (see Sammons et al., 2004; Melhuish et al., 2008; Sylva et al., 2010). The PHLE measure is an index created from the summation of seven items that record the frequency with which seven adult-child shared play and learning activities are carried out with preschool-aged children (3-5 years) using 7-point frequency scales with responses that range from 1 to 7 . The resulting PHLE measure that was constructed and used in the ECCE investigation had scores ranging from 7 to $49(\mathrm{n}=2,604$; mean $=30.59$; standard deviation $=9.08$ ). The items contributing to the PHLE, caregivers' response options to these items, and the median response options are shown in Table $\mathbf{1}$.

The statistical evaluation of the reliability and validity of the THLE scale that is reported in this paper was enriched through use of the additional data that were gathered by the ECCE study for the same sample of children and families who had their HLEs measured in the toddler and preschool years. Three sets of measures (child, primary caregiver, home environment) were included and used in different, though mutually informative, statistical appraisals of the THLE's reliability and measurement validity (analytic details below). Full descriptions of the measures used in the baseline assessment can be found in Maisey et al. (2013) and in Sammons et al. (2015a) for measures used at mean child age 38 months.

Table 2 presents summary descriptive statistics for the measures that were included in this study. The highest qualification (academic or vocational) held by each Primary caregiver (PCG) in a household was measured across individuals by comparing each reported qualification to its equivalent National Vocational Qualification (NVQ) level (where a higher NVQ level indicates a higher level of achieved qualification). Within this system an NVQ Level 1 captures qualifications equivalent to those from compulsory age 16 national assessments, and an NVQ Level 5 captures qualifications equivalent to (and including) university degrees (Lester, 2018). For readers unfamiliar with this practice of standardizing qualifications to NVQ levels, this is a method that has long been routine in United Kingdom educational practice, policy, and research (e.g. Dearden et al., 2002; Gayle et al., 2015).

Looking at the other measures presented within Table 2 that may require further explanation, within the home tenure measure, the "rent free" category captured households who were legally living, at zero cost, in a property that was owned by someone else (e.g. a friend or a relative). This category does not include households whose accommodation was lived in illegally, accommodation that was financially contributed to by the United Kingdom State due to low household income (this would still be rented accommodation), or accommodation that was owned (with or without a mortgage) by one or more members of the household. PCG mental health/well-being was measured via the General Health Questionnaire (GHQ; Goldberg and Williams, 1988) when children were both 14 ('baseline'/ toddler; (Cronbach's $a=0.88$; Cronbach, 1951) and 38 
("outcome"/pre-schooler) months of age ( $\alpha=0.88$; see Sammons et al., 2015a). Parental stress was also measured at both these ages through use of the 'Parental distress' subscale of the Parenting Stress Index (PSI; Abidin, 1995; alpha at $14 \mathrm{~m}=0.95$ and at $38 \mathrm{~m}=0.92)$.

\section{Analytic Approach}

The statistical appraisal of the reliability and validity of the THLE items and the resulting THLE scale was grounded in Classical Test Theory (CTT) and was undertaken in two stages using a combination of SPSS version 24 (IBM Corporation, 2016), JASP version 0.10.2 (JASP Team, 2019), and Mplus version 7.4 (Muthén and Muthén, 2015). First, reliability was investigated using a mix of item-level analysis, statistical estimators, and confirmatory factor analyses that provided complementary lenses through which to examine the internal consistency of different combinations of the ten THLE and toddler television watching items within the baseline sample of 5,717 families. Second, the measurement validity of the THLE was appraised through statistical analyses of different aspects of criterion and construct validity (and via comparison with PHLE scores) within the longitudinal sample of 2,608 families.

To investigate the reliability of the THLE items, a range of statistical analyses were undertaken of the eight THLE items and two toddler television-watching items to determine their ability to serve as reliable indicators of an underlying latent THLE. First, Spearman correlation coefficients $\left(r_{s}\right)$ were used to consider the degree of shared response between each pair of items. Second, the Cronbach's alpha statistic was then used to appraise each potential item's contribution to an overall THLE scale. However, this analysis of the internal consistency of the items also responded to contemporary criticisms of the trustworthiness of Cronbach's alpha for this purpose (e.g. Sijtsma, 2009; Dunn et al., 2014). As a result, internal consistency was also appraised through estimation of Guttmann's (1945) five other lambda statistics $(\lambda 1, \lambda 2$, plus $\lambda 4$ through $\lambda 6$; Cronbach's $\alpha=\lambda 3$; see Sijtsma, 2009) and McDonald's omega ( $\omega$; McDonald, 1999). We also acknowledged the common practice of accepting the critical cutoff value for an acceptable alpha of 0.70 (Nunnally and Bernstein, 1994) but are aware of the limitation of accepting 0.70, or any other value, as a binary cut-off (Dunn et al., 2014). Finally, a Confirmatory Factor Analysis was undertaken of those items that the prior procedures had indicated demonstrated sufficient consistency to evidence an underlying (THLE) scale -- this to test the appropriateness of the unidimensional latent (THLE) construct (via model fit with data) that the prior statistical analyses pointed to.

Following from the reliability analyses, the association between the resulting THLE scale and the varying ages of the toddlers within the ECCE sample was then assessed because of the consequences that the fast pace of development at this age might have for the forms of adult-child shared play and learning activities that are developmentally appropriate. The result of this analysis was the development of an age-adjusted THLE scale (adj.THLE) that, along with a THLE scale that was based upon summation of items, was taken forward into the second stage of the analysis in this paper.

With a THLE scale developed from indicative items and demonstrating internal consistency, Stage two of the analysis then considered the measurement validity of the THLE through statistical procedures that made use of other measures collected by the ECCE researchers and that built on past published work (Sammons et al., 2015a) showing the THLE as a significant predictor of child cognition and behavior at mean age 38 months (see the Introduction). The result was a mix of statistical assessments that combined aspects of criterion validity (via concurrent and predictive validity) with aspects of construct validity (via convergent and discriminant validity). This began with consideration of the association shared between the two forms of the THLE and then progressed to consideration of the association between the THLE and the PHLE to evaluate the new scale's predictive convergent validity over time (from average age 14 months to average age 38 months).

Second, the associations between the THLE (in both simple and age-adjusted forms) and other measures taken at the baseline (toddler) assessment point of the ECCE study were then estimated in order to evaluate the THLE's concurrent (and predicted) convergent and discriminant validity. These associations were also compared to equivalent associations for the PHLE in order to demonstrate how HLEs prior to school entry can be stratified both consistently and uniquely when comparing the toddler years to the preschool years for the same sample. Multilevel statistical regression models that accounted for the nesting of families within children's centers (a key feature of the ECCE sampling strategy) were used for these analyses. If the association between the THLE and demographics were found to be similar to the associations between the PHLE and various key demographics, then this would provide further evidence of measurement validity across both the criterion and construct domains. To facilitate this comparison between the THLE and PHLE, multilevel effect sizes were calculated following the approach used by Elliot and Sammons (2004).

An examination of the proportions of variance in the THLE and PHLE scores that were attributable to differences between SSCCs (rather between families; via Intra Class Correlations, ICCs) provided further support for the use of multilevel statistical regression models. Hox (2010) describes ICC values of 5, 10, and 15\% as showing a small, medium and high effect of a nested sample design. Here, the THLE returned an ICC of $15 \%$ (SSCC variance $=8.10, p<0.001$ ), the ageadjusted THLE an ICC of $15 \%$ (SSCC variance $=0.13, p<0.001$ ), and the PHLE an ICC of $5 \%$ (SSCC variance $=4.20, p<0.001$ ). Thus, the nested design of the ECCE study resulted in non-trivial variation in THLE scores due to differences between SSCCs-variation captured by the multilevel regression models. Further, using this modeling approach for all of the HLE variables provided a consistent basis of comparison for demographic correlates across the THLE and PHLE.

\section{RESULTS}

\section{Reliability}

\section{Item-Level Analysis}

Further considering the descriptive statistics presented in Table 1, the medians and distributions of the THLE items and toddler television watching items demonstrated that these items were 
TABLE 3 | Bivariate associations between the eight items measuring the Toddler Home Learning Environment and two items measuring toddlers' television watching environments (Spearman's Correlations, $r_{\mathrm{s}}$ )

\begin{tabular}{|c|c|c|c|c|c|c|c|c|c|c|c|}
\hline \multicolumn{2}{|l|}{ THLE and television watching items } & \multirow{2}{*}{$\begin{array}{l}1 \\
1\end{array}$} & \multirow[t]{2}{*}{2} & \multirow[t]{2}{*}{3} & \multirow[t]{2}{*}{4} & \multirow[t]{2}{*}{5} & \multirow[t]{2}{*}{6} & \multirow[t]{2}{*}{7} & \multirow[t]{2}{*}{8} & \multirow[t]{2}{*}{ A } & \multirow[t]{2}{*}{ B } \\
\hline 1. How often does someone at home take (child) out of the & $r_{\mathrm{s}}$ & & & & & & & & & & \\
\hline $\begin{array}{l}\text { house, for example visiting family or friends, or going to the } \\
\text { park? }\end{array}$ & $\mathrm{n}$ & 5,714 & & & & & & & & & \\
\hline 2. How often does someone at home draw (child)'s & $r_{\mathrm{s}}$ & $0.20^{\star \star \star}$ & 1 & & & & & & & & \\
\hline $\begin{array}{l}\text { attention to the names of things during their day-to-day } \\
\text { activities? }\end{array}$ & $\mathrm{n}$ & 5,711 & 5,712 & & & & & & & & \\
\hline 3. How often does someone use blocks or shape sorting & $r_{s}$ & $0.17^{\star \star \star}$ & $0.31^{\star \star \star}$ & 1 & & & & & & & \\
\hline toys with (child)? & $\mathrm{n}$ & 5,709 & 5,708 & 5,710 & & & & & & & \\
\hline 4. How often does someone at home talk about, or try to & $r_{\mathrm{s}}$ & $0.16^{\star \star \star}$ & $0.33^{\star \star \star}$ & $0.49^{\star \star \star}$ & 1 & & & & & & \\
\hline teach (child) the names of colors or shapes? & $\mathrm{n}$ & 5,710 & 5,709 & 5,708 & 5,711 & & & & & & \\
\hline 5. How often does someone at home sing songs or & $r_{s}$ & $0.14^{\star \star \star}$ & $0.33^{\star \star \star}$ & $0.29^{\star \star \star}$ & $0.34^{\star * \star}$ & 1 & & & & & \\
\hline nursery rhymes to or with (child)? & $\mathrm{n}$ & 5,711 & 5,710 & 5,708 & 5,709 & 5,712 & & & & & \\
\hline 6. How often does (child) get a chance to play in a messy & $r_{s}$ & $0.11^{\star \star \star}$ & $0.12^{\star \star \star}$ & $0.16^{\star \star \star}$ & $0.18^{\star \star \star}$ & $0.13^{\star \star \star}$ & 1 & & & & \\
\hline way, for example using playdough, paints, or sand? & $\mathrm{n}$ & 5,709 & 5,708 & 5,706 & 5,707 & 5,708 & 5,710 & & & & \\
\hline 7. Although (child) is very young, some children do enjoy & $r_{s}$ & $0.22^{\star \star \star}$ & $0.29^{\star \star \star}$ & $0.27^{\star \star \star}$ & $0.34^{\star \star \star}$ & $0.33^{\star \star \star}$ & $0.22^{\star \star \star}$ & 1 & & & \\
\hline $\begin{array}{l}\text { being read to or handling books designed for babies. How } \\
\text { often does someone at home read to (child)? }\end{array}$ & $\mathrm{n}$ & 5,712 & 5,711 & 5,709 & 5,710 & 5,711 & 5,709 & 5,713 & & & \\
\hline 8. How many books written for babies or toddlers does & $r_{\mathrm{s}}$ & $0.22^{\star \star \star}$ & $0.25^{\star \star \star}$ & $0.19^{\star \star \star}$ & $0.23^{\star \star *}$ & $0.20^{\star \star *}$ & $0.25^{\star \star \star}$ & $0.45^{\star \star \star}$ & 1 & & \\
\hline (child) have? & $\mathrm{n}$ & 5,711 & 5,710 & 5,708 & 5,709 & 5,710 & 5,708 & 5,711 & 5,712 & & \\
\hline A. How much time the child spends watching TV on their & $r_{\mathrm{s}}$ & $-11^{\star \star \star}$ & $-0.12^{\star \star \star}$ & $-0.07^{\star \star \star}$ & $-0.07^{\star \star \star}$ & $-0.10^{\star \star \star}$ & $-0.04^{\star \star \star}$ & $-0.10^{\star \star \star}$ & $-0.11^{\star \star \star}$ & 1 & \\
\hline own, while someone else is busy in the household? & $\mathrm{n}$ & 5,707 & 5,706 & 5,705 & 5,705 & 5,706 & 5,704 & 5,707 & 5,706 & 5,708 & \\
\hline B. How much time the child spends watching TV together & $r_{s}$ & $-11^{\star \star \star}$ & $-07^{\star \star \star}$ & 0.00 & 0.02 & $-0.05^{\star \star \star}$ & -0.02 & $-0.05^{\star \star \star}$ & $-0.10^{\star \star \star}$ & $0.47^{\star \star \star}$ & 1 \\
\hline with someone at home? & $\mathrm{n}$ & 5,708 & 5,707 & 5,705 & 5,706 & 5,707 & 5,705 & 5,708 & 5,707 & 5,705 & 5,709 \\
\hline
\end{tabular}

${ }^{*} \mathrm{p}<0.05 ;{ }^{* *} \mathrm{p}<0.01 ;{ }^{* * *} \mathrm{p}<0.001$.

differentially sensitive to the frequency with which different activities took place in the home. None of the ten items had blank responses for any of their seven response options (the least frequent response, from 29 respondents, was, "less than once a week" regarding how often a child's attention was drawn to the names of things) and these items differed from one another as regards which of the activities were more and less common for toddlers to experience. The most frequent activities included the child having their attention focused on the names of objects during day-to- day activities, and exposure to songs or nursery rhymes (shared or otherwise). The average child was reported by primary caregivers as experiencing both of these activities more than once a day. Slightly less frequently experienced (once a day for the average toddler) were someone using blocks or shape sorting toys with the child, teaching them the names of colors and/or shapes, and someone reading to the child. By contrast, the average toddler engaged in messy play much less frequently--on average reported only once or twice (at all); although with a high degree of variation (e.g. 8.1\% of caregivers reported their child engaged in messy play every day or more often). Caregivers reported having an average of 11-15 books written for babies or toddlers at home-again there was substantial variation around this average (e.g. $2.5 \%$ of respondents reported their child to have no such books - 142 families). When it came to toddlers' television watching, this was reported as very infrequent (30 min or less each day) by caregivers irrespective of whether this was solo or shared television watching. Again, there was notable variation to this. For example, 171 caregivers ( $3 \%$ of the baseline sample) reported four or more hours of shared television watching while 95 reported that their toddler watched $3+$ hours of television by themselves every day.
Table 3 illustrates the bivariate associations between the eight measures of THLE and the two measures of toddlers' television watching. The variation between the THLE and television watching items in terms of their averages is apparent within this table as are the topics (shared or otherwise) that the items focused upon. The responses to the items were most similar (via highest correlation coefficients) for items that shared a focus. For example, activities focused upon shapes and their names (items 3 and $\left.4, \mathrm{r}_{\mathrm{s}}=0.49, p<0.001\right)$, the frequency with which toddlers were read to and the number of books that they have $\left(r_{\mathrm{s}}=0.45\right.$, $p<0.0001$ ), and how much time a toddler spends watching television either solo or shared with someone else $\left(r_{s}=0.47, p<\right.$ $0.0001)$. It is notable that the association between the television watching items and the THLE items, while negative, is very small (in terms of the magnitude of the correlation coefficients). This suggests that it is not the case that the toddlers in this sample experienced more frequent television watching in place of developmentally stimulating activities shared with adults, but rather that these are separate reported activities that all toddlers experience but on a more or less frequent basis.

\section{Internal consistency}

The internal consistency of four possible and alternative THLE scales was statistically appraised via Guttmann's lambdas, Cronbach's alpha, and McDonald's omega (see Table 4). The four possible alternative THLE scales varied from one another as regards their inclusion of the two-toddler television watching items: included, alternatively excluded, and both excluded. Internal consistency was highest (across all seven statistical estimators of internal consistency) when the two television watching items were excluded - notably passing the commonly 
TABLE 4 | Internal consistency of the ten items measuring the Toddler Home Learning Environment and toddlers' television watching (Cronbach's a, Guttmann's $\lambda$ s, and McDonald's $\omega)$.

\begin{tabular}{|c|c|c|c|c|}
\hline Statistic & $\begin{array}{l}\text { Including all ten } \\
\text { items }(n=5,688)\end{array}$ & $\begin{array}{l}\text { Excluding watching TV } \\
\text { on own }(n=5,691)\end{array}$ & $\begin{array}{l}\text { Excluding watching TV } \\
\text { with adult }(n=5,691)\end{array}$ & $\begin{array}{l}\text { Excluding both watching } \\
\text { TV items }(n=5,696)\end{array}$ \\
\hline$\lambda 1$ & 0.57 & 0.59 & 0.59 & 0.62 \\
\hline$\lambda 2$ & 0.66 & 0.68 & 0.69 & 0.72 \\
\hline$\lambda 3, a$ & 0.63 & 0.66 & 0.66 & 0.71 \\
\hline$\lambda 4$ & 0.53 & 0.59 & 0.59 & 0.66 \\
\hline$\lambda 5$ & 0.65 & 0.67 & 0.68 & 0.71 \\
\hline$\lambda 6$ & 0.66 & 0.67 & 0.67 & 0.70 \\
\hline$\omega$ & 0.65 & 0.68 & 0.68 & 0.73 \\
\hline
\end{tabular}

accepted critical threshold value for $a$ of 0.70 -and a finding that was in-keeping with the low correlations between the THLE and television watching items shown in Table 3. Notably, when each of the eight THLE items was considered for exclusion in order to increase the overall consistency of the other items, no increase in the values of the lambdas or omega coefficients were returned (which would indicate an opportunity for a scale comprised of items with greater internal consistency). This suggested that a THLE scale should be created that drew upon all eight of the THLE items and none of the items measuring toddler television watching.

The appropriateness of a unidimensional THLE scale comprised of the eight THLE items was then statistical evaluated through specification of a Confirmatory Factor Analysis (CFA) and appraisal of the fit of this model to the ECCE data to which it was applied. This CFA modified standard errors to take account of the nesting of families within SSCCs and, informed by the correlations above, specified correlated residuals between the two shapes and space items $(\mathrm{r}=0.23, p<0.001)$ and between the two items related to books $(r=0.24, p<0.001$; note that IRT modeling is not suitable when such correlations exist (DeMars, 2010) and that the modeling of correlated residuals in CFA is common practice though still subject to debate; see Bandalos, 2021). The resulting CFA demonstrated model fit that is commonly regarded as acceptable according to both the Root Mean Square Error Of Approximation (RMSEA) $=0.036$ (90\% confidence interval: 0.031 to 0.042 ) and the Comparative Fit Index $(\mathrm{CFI})=0.978$ (e.g. Rigdon, 1996). Standardized factor loadings varied in magnitude from 0.33 (frequency of messy play) to 0.60 (frequency of being read to). The results of the CFA procedure confirmed the appropriateness of specifying a single THLE scale from the eight THLE items.

Once the items were identified that could consistently reflect a common response from caregivers as regards their toddler's home learning environment, a THLE scale was created through summation of these (eight) items -- summation being used in order to create a THLE measure that matched the format of the PHLE measure upon which the THLE was based. With a THLE measure created, the final step undertaken in assessment of the reliability of the THLE was to appraise the THLE measure for its stratification by the age-range of the $n=5,717$ children sampled by ECCE at baseline (when the average child was 14 months old). A small but significant association was found $(\mathrm{r}=0.20, p<0.001, \mathrm{n}=5,687)$ indicating a slight bias in the THLE
TABLE 5 | Descriptive statistics of the toddler home learning environment (THLE), child age-adjusted toddler home learning environment (adj.THLE) and preschool home learning environment (PHLE) measures.

\begin{tabular}{lccccc}
\hline HLE measure & Mean & SD & Skewness & Kurtosis & $\mathbf{n}$ \\
\hline THLE & 42.70 & 7.68 & -0.94 & 0.84 & 5,696 \\
adj.THLE & 0.00 & 1.00 & -0.94 & 0.91 & 5,696 \\
PHLE & 30.59 & 9.08 & -0.21 & -0.49 & 2,604 \\
\hline
\end{tabular}

scale: older children were somewhat more likely to receive a higher THLE score. In response, a child age-adjusted version of the THLE scale was developed by first regressing the THLE scale on the toddlers' ages, saving the standardized residuals, and then $\mathrm{Z}$-scoring these residual values. The result was an age-adjusted THLE scale (adj.THLE) that while still highly correlated with the THLE scale $(\mathrm{r}=0.98, p<0.001, \mathrm{n}=5,696)$ was now zero correlated with the age of children who took part in the baseline ECCE survey of families $(\mathrm{r}=0.00, p=1.000, \mathrm{n}=$ 5,687). Table 5 shows the means and distributions of the THLE, adj.THLE, and for comparison, the PHLE measure. For comparative purposes it is worth noting that the PHLE scale was not associated with the children's ages, either at mean age 14 months $(\mathrm{r}=0.02, p=0.262, \mathrm{n}=2,603)$ or at mean age 38 months $(\mathrm{r}=0.02, p=0.364, \mathrm{n}=2,604)$.

\section{Measurement Validity}

The association between children's Home Learning Environments over time (appraising predictive criterion validity with convergent construct validity). With two versions of a THLE scale created (one via simple summation of the eight THLE items, the other adjusted for the sampled toddlers' ages), the second stage of the statistical analyses considered the degree to which the THLE related to other measures in the ECCE dataset. First, the extent to which the THLE was associated with the PHLE was considered -- this to explore the consistency with which higher or lower THLE scores were likely to remain as such on average 24 months later (at mean child age 38 months). There was a moderate positive association shared between the THLE and PHLE over time $(\mathrm{r}=0.36, p<0.001, \mathrm{n}=2,595)$ with this equal in size and statistical significance to that shared between the ageadjusted THLE and PHLE $(\mathrm{r}=0.36, p<0.001, \mathrm{n}=2,595)$. Thus there was a tendency for a home learning environment to remain relatively stable-home learning environments around age 1 that 
TABLE 6 | Multilevel regression showing associations between demographics and the toddler home learning environment scale (THLE; $n=2,404$ of the longitudinal $n=$ 2,608).

\begin{tabular}{|c|c|c|c|c|c|c|}
\hline \multirow[t]{2}{*}{ DV } & \multirow[t]{2}{*}{ Independent variable } & \multicolumn{2}{|c|}{ Model 0} & \multicolumn{3}{|c|}{ Model 1} \\
\hline & & B & S.E. & B & S.E. & Effect size \\
\hline \multirow[t]{22}{*}{ THLE } & Intercept & $43.22^{\star \star \star}$ & 0.30 & $27.54^{\star \star \star}$ & 2.25 & \\
\hline & Child gender: Male & & & 0.21 & 0.25 & 0.03 \\
\hline & Child's age at "baseline" & & & $0.52^{\star \star \star}$ & 0.05 & 0.45 \\
\hline & Mother's age at "baseline" & & & -0.01 & 0.03 & -0.02 \\
\hline & (Concurrent) caregiver mental health/well-being & & & -0.01 & 0.02 & -0.04 \\
\hline & (Concurrent) parenting stress & & & $-0.05^{\star \star \star}$ & 0.01 & -0.26 \\
\hline & Highest caregiver qualification (equivalent): NVQ1' & & & $2.15^{\star}$ & 0.83 & 0.33 \\
\hline & NVQ2' & & & $3.12^{\star \star \star}$ & 0.67 & 0.49 \\
\hline & NVQ3' & & & $4.05^{\star \star \star}$ & 0.70 & 0.63 \\
\hline & NVQ4' & & & $4.35^{\star \star \star}$ & 0.69 & 0.68 \\
\hline & NVQ5' & & & $4.95^{\star \star \star}$ & 0.74 & 0.77 \\
\hline & Other' & & & $1.95^{\star}$ & 0.97 & 0.30 \\
\hline & Tenure: Rent it" & & & $2.77^{\star \star}$ & 0.98 & 0.43 \\
\hline & Shared ownership" & & & $2.79^{\star \star \star}$ & 0.78 & 0.43 \\
\hline & Mortgage" & & & 2.36 & 1.28 & 0.37 \\
\hline & Own it outright" & & & 1.38 & 0.78 & 0.21 \\
\hline & Household income: <£4.999"' & & & -0.66 & 0.89 & -0.10 \\
\hline & $£ 5.000-£ 9.999^{\prime \prime \prime}$ & & & -0.77 & 0.55 & -0.15 \\
\hline & $£ 10.000-£ 19.999^{\prime \prime \prime}$ & & & $-1.34^{\star \star}$ & 0.44 & -0.21 \\
\hline & £20.000-£29.999'"' & & & $-1.16^{\star *}$ & 0.42 & -0.18 \\
\hline & $£ 30.000-£ 39.999^{\prime \prime \prime}$ & & & 0.09 & 0.43 & 0.01 \\
\hline & $£ 40.000-£ 49.999^{\prime \prime \prime}$ & & & 0.40 & 0.45 & 0.06 \\
\hline \multicolumn{2}{|c|}{ Model fit: $-2^{\star}$ loglikelihood } & $17,438.16$ & & $15,615.14$ & & \\
\hline \multicolumn{2}{|c|}{ Model fit: $\Delta-2^{*}$ loglikelihood } & & & 1823.02 & & \\
\hline \multicolumn{2}{|c|}{ Intra class correlation } & 0.15 & & $0.10^{\prime \prime \prime \prime}$ & & \\
\hline \multicolumn{7}{|c|}{ Unexplained variance: } \\
\hline \multicolumn{2}{|c|}{ Sure start Children's centers (SSCCs) } & 8.10 & & 4.29 & & \\
\hline \multicolumn{2}{|c|}{ Families } & 44.80 & & 36.62 & & \\
\hline \multicolumn{7}{|c|}{ Proportion of variance explained: } \\
\hline \multicolumn{2}{|c|}{ SSCCS } & & & 0.47 & & \\
\hline \multicolumn{2}{|c|}{ Families } & & & 0.18 & & \\
\hline
\end{tabular}

${ }^{*} \mathrm{p}<0.05 ;{ }^{* *} \mathrm{p}<0.01 ;{ }^{* *} \mathrm{p}<0.001 ; \mathrm{DV}$, dependent variable; NVQ, national vocational qualification (equivalent level); 'reference category, No qualifications; "reference category, Tenure (Rent free); "'reference category, household income > £50,000; intra class correlation, the proportion of variation in THLE scores attributable to differences between SSCCs rather than differences between families; '"'residual intra class correlation.

comprised less frequent adult-child activities tended to remain stable as did environments where these activities were much more frequently experienced. More pertinent to the purpose of this paper, this tendency for THLE scores to statistically predict PHLE scores supports the construct validity of the THLE (it was adapted from the PHLE so was conceptually related to it) and its predictive validity (earlier HLE scores should be associated with later HLE scores).

The statistical predictors of children's Home Learning Environments (appraising criterion validity with discriminant construct validity). Although the range of caregiver responses to the THLE and PHLE were similar to one another and this provides evidence of the measurement validity of the THLE, further statistical comparison of the scales is possible to more thoroughly interrogate the measurement validity of the THLE. This was achieved by comparing the extent to which THLE and PHLE scores were statistically associated with a variety of demographic measures differentiating the 2,608 families who took part in the longitudinal survey of families (and following a similar approach to that of Toth et al., 2020 for older age groups within the EPPE study within which the PHLE was developed).
By looking at only the 2,608 families who participated in the longitudinal study, and not the 5,717 who took part in the baseline survey, a consistent sample is studied which makes for reliable comparison of demographic correlates of the THLE and PHLE.

Tables 6, 7 show the results of the multilevel regression models that considered the extent to which demographic factors were associated with THLE scores. The results shown in Table 7 broadly match those shown in Table 6, which was expected given the earlier correlation of $r=0.98$ between the THLE and its child age-adjusted counterpart (see above). However, only Table 6 (not Table 7) includes child age (at baseline assessment) as an independent variable-this as a statistical control to facilitate fairer comparison of demographic correlates across the two versions of the THLE scale. The demographic predictors of the THLE and child age-adjusted THLE scales are broadly equivalent. Toddlers were significantly likely to experience more stimulating home learning environments when their caregivers experienced less parenting stress, when their primary caregiver held higher academic qualifications, when families were not living in rent- 
TABLE 7 | Multilevel regression showing associations between demographics and the child age-adjusted Toddler Home Learning Environment Scale (adj. THLE; $\mathrm{n}=2,404$ of the longitudinal $n=2,608)$.

\begin{tabular}{|c|c|c|c|c|c|c|}
\hline \multirow[t]{2}{*}{ DV } & \multirow[t]{2}{*}{ Independent variable } & \multicolumn{2}{|c|}{ Model 0} & \multicolumn{3}{|c|}{ Model 1} \\
\hline & & B & S.E. & B & S.E. & Effect size \\
\hline \multirow[t]{21}{*}{ Adj.THLE } & Intercept & 0.06 & 0.04 & $-0.11^{\star \star \star}$ & 0.28 & \\
\hline & Child gender: Male & & & 0.03 & 0.03 & 0.04 \\
\hline & Mother's age at "baseline" & & & 0.00 & 0.00 & 0.00 \\
\hline & (Concurrent) caregiver mental health/well-being & & & 0.00 & 0.00 & 0.00 \\
\hline & (Concurrent) parenting stress & & & $-0.01^{\star \star \star}$ & 0.00 & -0.40 \\
\hline & Highest caregiver qualification (equivalent): NVQ1' & & & $0.28^{\star}$ & 0.11 & 0.33 \\
\hline & NVQ2' & & & $0.42^{\star \star \star}$ & 0.09 & 0.49 \\
\hline & NVQ3' & & & $0.54^{\star \star \star}$ & 0.09 & 0.64 \\
\hline & NVQ4' & & & $0.58^{\star \star \star}$ & 0.09 & 0.68 \\
\hline & NVQ5' & & & $0.67^{\star \star \star}$ & 0.10 & 0.79 \\
\hline & Other' $^{\prime}$ & & & $0.27^{\star}$ & 0.13 & 0.32 \\
\hline & Tenure: Rent it" & & & $0.37^{\star \star}$ & 0.13 & 0.44 \\
\hline & Shared ownership" & & & $0.38^{\star \star \star}$ & 0.10 & 0.45 \\
\hline & Mortgage" & & & 0.31 & 0.17 & 0.37 \\
\hline & Own it outright" & & & 0.19 & 0.10 & 0.22 \\
\hline & Household income: < £4.999'"' & & & -0.09 & 0.12 & -0.11 \\
\hline & $£ 5.000-£ 9.999^{\prime \prime \prime}$ & & & -0.11 & 0.07 & -0.13 \\
\hline & $£ 10.000-£ 19.999^{\prime \prime \prime}$ & & & $-0.18^{\star \star}$ & 0.06 & -0.21 \\
\hline & $£ 20.000-£ 29.999^{\prime \prime \prime}$ & & & $-0.15^{\star \star}$ & 0.06 & -0.18 \\
\hline & $£ 30.000-£ 39.999^{\prime \prime \prime}$ & & & 0.01 & 0.06 & 0.01 \\
\hline & $£ 40.000-£ 49.999^{\prime \prime \prime}$ & & & 0.05 & 0.06 & 0.06 \\
\hline \multicolumn{2}{|c|}{ Model fit: $-2 *$ loglikelihood } & $6,838.90$ & & $5,903.45$ & & \\
\hline \multicolumn{2}{|c|}{ Model fit: $\Delta-2^{\star}$ loglikelihood } & & & 935.45 & & \\
\hline \multicolumn{2}{|c|}{ Intra class correlation } & 0.15 & & $0.10^{\prime \prime \prime \prime}$ & & \\
\hline \multicolumn{7}{|c|}{ Unexplained variance: } \\
\hline \multicolumn{2}{|c|}{ Sure start Children's centers (SSCCs) } & 0.13 & & 0.07 & & \\
\hline \multicolumn{2}{|c|}{ Families } & 0.76 & & 0.64 & & \\
\hline \multicolumn{7}{|c|}{ Proportion of variance explained: } \\
\hline \multicolumn{2}{|c|}{ SSCCS } & & & 0.46 & & \\
\hline \multicolumn{2}{|l|}{ Families } & & & 0.16 & & \\
\hline
\end{tabular}

Note: ${ }^{*} \mathrm{p}<0.05 ;{ }^{* *} \mathrm{p}<0.01 ;{ }^{* * *} \mathrm{p}<0.001 ; \mathrm{DV}$, dependent variable; NVQ, national vocational qualification (equivalent level); Highest PCG Q, highest primary caregiver qualification; 'reference category, No qualifications; "reference category, tenure (rent free); "'reference category: household income > £ 50,000; intra class correlation, the proportion of variation in adj.THLE scores attributable to differences between SSCCs rather than differences between families; "''residual intra class correlation.

free accommodation, and where a family's household income was higher. Further, THLE scores were consistently not associated with a child's gender, a mother's age, or the primary caregiver's mental health/well-being. The largest association between THLE (either version) and family demographics was that shared with the primary caregiver's highest held academic qualifications (by effect size). The second largest association was with child age at baseline assessment (Table 7)-hence providing further support for our consideration of a version of the THLE that was adjusted for the sampled toddler's age in months.

Comparing the demographic correlates of THLE scores (Tables 6, 7) with PHLE scores (Table 8), both similarities and differences can be observed. Considering similarities first, the primary caregiver's level of academic qualification remained the single largest statistical correlate of the extent to which children were likely to experience more stimulating HLEs. Furthermore, the more parenting stress that was experienced by a child's caregivers (in either the toddler or preschool periods) the less stimulating the average HLE was likely to be. In addition, the extent to which an HLE was likely to be more or less stimulating was consistently not associated with either a mother's age or the primary caregiver's mental health/ wellbeing. An over-arching similarity is that the proportions of variation in HLE scores that were explained by these predictors remained very similar across the age-adjusted toddler and preschool HLE measures. Around three times the variation in HLEs at the level of SSCCs was explained by family characteristics, as was variation between the families themselves (adj.THLE: 0.46 vs. 0.16; PHLE: 0.33 vs. 0.09). It is possible that this reflects the location of the sampled SSCCs in neighbourhoods classified as more disadvantaged but being open to all individual families who wished to use them (see Sylva et al., 2015).

Considering next the differences between the demographic correlates of the THLE and PHLE, while THLE scores were differentiated by child age, household income, and the tenure status of a family's home, this was not found for the PHLE. Instead, PHLE scores were differentiated by child gender with the average boy likely to experience a significantly less stimulating preschool HLE than the average girl. The implications for the measurement validity of the THLE scale from these findings are mixed. The measurement validity of the THLE is supported by the similarities between the results, but the differences between the correlates of the THLE and PHLE scales require comparison 
TABLE 8 | Multilevel Regression showing demographic correlates with the preschool home learning environment scale $(\mathrm{PHLE} ; \mathrm{n}=2,409$ of the longitudinal $n=2,608)$.

\begin{tabular}{|c|c|c|c|c|c|c|}
\hline \multirow[t]{2}{*}{ DV } & \multirow[t]{2}{*}{ Independent variable } & \multicolumn{2}{|c|}{ Model 0} & \multicolumn{3}{|c|}{ Model 1} \\
\hline & & B & S.E. & B & S.E. & Effect size \\
\hline \multirow[t]{22}{*}{ PHLE } & Intercept & $30.49^{\star \star \star}$ & 0.26 & $31.91^{\star \star \star}$ & 3.04 & \\
\hline & Child gender: Male & & & $-2.23^{\star \star \star}$ & 0.35 & -0.26 \\
\hline & Child's age at "outcome" & & & 0.03 & 0.06 & 0.02 \\
\hline & Mother's age at "baseline" & & & -0.01 & 0.03 & -0.01 \\
\hline & (Concurrent) caregiver mental health/well-being & & & -0.02 & 0.08 & -0.01 \\
\hline & (Concurrent) parenting stress & & & $-0.11^{\star \star \star}$ & 0.03 & -0.20 \\
\hline & Highest caregiver qualification: NVQ1' & & & 0.44 & 1.13 & 0.05 \\
\hline & NVQ2' & & & 1.02 & 0.92 & 0.12 \\
\hline & NVQ3' & & & $3.36^{\star \star \star}$ & 0.94 & 0.40 \\
\hline & NVQ4' & & & $4.68^{\star \star \star}$ & 0.92 & 0.55 \\
\hline & NVQ5' & & & $5.26^{\star \star \star}$ & 0.99 & 0.62 \\
\hline & Other' & & & $3.52^{\star \star}$ & & 0.42 \\
\hline & Tenure: Rent it" & & & 1.51 & 1.37 & 0.18 \\
\hline & Shared ownership" & & & 1.10 & 1.12 & 0.13 \\
\hline & Mortgage" & & & 0.50 & 1.86 & 0.06 \\
\hline & Own it outright" & & & 0.58 & 1.12 & 0.07 \\
\hline & Household income: < £4.999'"' & & & -0.10 & 1.24 & -0.01 \\
\hline & $£ 5.000-£ 9.999^{\prime \prime \prime}$ & & & 0.11 & 0.75 & 0.01 \\
\hline & $£ 10.000-£ 19.999^{\prime \prime \prime}$ & & & 0.38 & 0.60 & 0.04 \\
\hline & $£ 20.000-£ 29.999^{\prime \prime \prime}$ & & & -0.03 & 0.57 & 0.00 \\
\hline & $£ 30.000-£ 39.999^{\prime \prime \prime}$ & & & 0.37 & 0.59 & 0.04 \\
\hline & $£ 40.000-£ 49.999^{\prime \prime \prime}$ & & & 0.85 & 0.62 & 0.10 \\
\hline \multicolumn{2}{|c|}{ Model fit: $-2 *$ loglikelihood } & $18,845.21$ & & $17,192.67$ & & \\
\hline \multicolumn{2}{|c|}{ Model fit: $\Delta-2^{\star}$ loglikelihood } & & & $1,652.54$ & & \\
\hline \multicolumn{2}{|c|}{ Intra class correlation } & 0.05 & & $0.04^{\prime \prime \prime \prime}$ & & \\
\hline \multicolumn{7}{|c|}{ Unexplained variance: } \\
\hline \multicolumn{2}{|c|}{ Sure start Children's centers (SSCCs) } & 4.20 & & 2.81 & & \\
\hline \multicolumn{2}{|c|}{ Families } & 78.67 & & 71.61 & & \\
\hline \multicolumn{7}{|c|}{ Proportion of variance explained: } \\
\hline \multicolumn{2}{|c|}{ SSCCS } & & & 0.33 & & \\
\hline \multicolumn{2}{|c|}{ Families } & & & 0.09 & & \\
\hline
\end{tabular}

${ }^{*} \mathrm{p}<0.05 ;{ }^{* *} \mathrm{p}<0.01 ;{ }^{* * *} \mathrm{p}<0.001 ; \mathrm{DV}$, Dependent Variable; NVQ, National Vocational Qualification (equivalent level); 'reference category, No qualifications; "reference category, Tenure (Rent free); "'reference category, household income > £ 50,000; intra class correlation, the proportion of variation in PHLE scores attributable to differences between SSCCs rather than differences between families; "''residual intra class correlation.

to existing academic literature regarding age-related and gender variation in the known correlates of home environments. This is undertaken in the Discussion.

\section{DISCUSSION}

With the potential to serve as long-term predictors of a range of educational and developmental outcomes there is the requirement for early HLEs to be measured accurately. Further, while previous research has demonstrated the predictive power of the home learning environment in the preschool years (ages 3-5), less is known about the predictive power of the home learning environment for younger children. (Dodici et al., 2003). This paper responded to this issue by reporting the results from a series of analyses that investigated the reliability and validity of a new measure of the toddler home learning environment (THLE). This new measure was an adaption of a well-known existing measure of the preschool HLE developed by the longitudinal EPPSE investigation covering children age $3+$ to 16 years in England (see Sylva et al., 2010).

Comprised of eight items that reflected the degree to which toddlers experienced a more or less stimulating home learning environment, the results presented in this paper show that higher THLE scores were more likely to be reported for older toddlers. However, the meaning of this association is informed by the content of the eight THLE items and by the rapid rate of developmental change in the toddler years, particularly as regards language development (e.g. Rodriguez and TamisLeMonda, 2011). The THLE was designed to be sensitive to adult-child interactions across the toddler period and this obliged the inclusion of items that better reflected stimulation for older toddlers (particularly relating to text and words). Thus, our finding of higher THLE score for older children is in-keeping with what one would expect: for older toddler to more regularly experience activities related to texts and words as part of appropriate developmental scaffolding (see Granott, 2005).

However, there is a practical consequence from the association between THLE scores and the age of toddlers for how the THLE scale should be used in future. In circumstances where there is a wide age-range of toddlers whose home learning environments are to be assessed, the tendency for the THLE scale to return higher scores for older toddlers should be taken into account. This paper demonstrated two ways for this to be carried out that would lend themselves to future research: modification of the 
THLE scale or inclusion of child age in any multivariate statistical analyses that are subsequently undertaken. A third (simpler) alternative (potentially for use outside of research projects) would be for interpretations of THLE scores to demonstrate explicit understanding of the fact that THLE scores are likely to be higher for older toddlers. Of course, the inverse is also true: should the THLE be used with a narrow age range of toddlers then there is less of a need to take age-related variation in THLE scores into account in either THLE measurement, use in statistical analyses, or in subsequent interpretation. That said, less need does not imply no need.

The need for the measurement validity of the THLE to be appraised through a combination of statistical results and existing academic literature also extends beyond the association that the THLE shared with the age of toddlers --particularly given the consistencies and inconsistencies shared between the THLE and the PHLE. On one hand, the results of this paper showed a moderate degree of consistency between the THLE and PHLE. For example, a child's THLE score was shown to be broadly in line with their PHLE score twenty four months later, parenting stress and PCG academic qualifications were consistently associated with HLE scores at both ages, and PCG mental health/well-being was consistently not associated with either the THLE or PHLE. Such consistency (with the prior validated PHLE) lends support to claims of measurement validity with the new THLE.

On the other hand, toddlers' THLE scores were found to be uniquely stratified by child age, household income, and the household tenure of a family. Further, PHLE scores were uniquely stratified by child gender. At first glance, these inconsistencies may threaten claims of the THLE showing measurement validity. However, when interpreted through the lens of past research, these findings are more in-keeping with what one might expect. For example, the pace of developmental change in the toddler years fostering child age stratified THLE scores (as above). Alternatively, the increased emergence of child gender differentiated parent-child interaction favoring girls as children grow older is plausible (see Lovas, 2011). Further, the disappearance of income stratification (and household tenure status) in HLE scores by the preschool period could reflect the well-known increased risk for household instability in the preceding period (e.g. Weitzman, 1989; Buckner, 2014). When interpreted through the lens of past research then, the findings of this study suggest tentative (as it is just a single study) support for the THLE scale as a step-forward in the assessments of the HLE for very young children (toddlers) aged 9 to 18 months. We are certainly not aware of any past study that has carried out a validation study of a toddler HLE assessment with a sample of the size used here. Further work could explore how far there may be cross over in HLE measures for children age 19 to 36 months drawing on items from the THLE and PHLE. There may be overlap but it is plausible the THLE might still be useful up to age 24 months, while the PHLE again might extend down to 24 or to 30 months.

The strengths and limitations of this paper center upon the data that were used in the statistical analyses that were undertaken. First, the large sample size facilitated an appraisal of the ability of the THLE item responses scales to capture variation (all THLE response options were used). Second, the range of measures present within the large ECCE dataset facilitated a broad range of analyses to investigate the measurement validity of the THLE scale (remembering that this paper builds upon past working showing the THLE to significantly predict preschool period verbal cognitive abilities, non-verbal cognitive abilities, and prosocial behavior over and above a range of background measures; see Sammons et al., 2015a). The presence of both the THLE and the PHLE measures in the same dataset permitted a particularly powerful appraisal of measurement validity as one would expect THLE scores to relate to scores on the (prior validated) PHLE especially given that the THLE was an adaption of the PHLE.

Considering limitations, first the data comes from parental self-report and thus is subject to the biases inherent in this form of data (e.g. social desirability in the responses given-not uncommon in measures of the HLE; e.g. Lee and Xie, 2017; Peacock-Chambers et al., 2017). Second, the data lacked longterm educational and developmental outcomes by which to appraise the THLE relative to the PHLE. The project from which the data came (and within which the THLE was developed) was not designed to last long enough to obtain this data-certainly not the twelve years of the prospective longitudinal EPPSE investigation within which the PHLE was developed. Third, the Cronbach alpha estimate was at the lower-end of those commonly treated as acceptable. Fourth, no information was collected about tablet or smart phone use (including apps) by toddlers or pre-school children. This reflects the historic context when the ECCE study took place (such technology being much less common in 2010 when the first children were recruited to the evaluation). Although ECCE investigated television viewing alongside the HLE (as a kind of 'displacement activity'; Dore, et al., 2020), future research could also explore the extent to which smart phone and/or tablet use is related to other kinds of home learning activities for this very young age group. This would also help to inform the currently sparse and at-times contradictory evidence concerning how these devices (and apps on them) can benefit and/or hinder child development (e.g. Hall et al., 2019a).

\section{Implications for Researchers, Early Years Practitioners, and Policy Makers}

Given that this paper provides new evidence on the reliability and validity of the THLE scale, there are a number of implications for researchers, early years practitioners, and early years policy makers. First, there is much scope for further exploration of the long-term correlates of the THLE measure in future academic research (beyond preschool-period: HLE, verbal cognitive abilities, non-verbal cognitive abilities, and prosocial behaviors). One of the strengths of the PHLE measure (upon which the THLE is based) is that it has shown itself to be predictor of developmental and educational outcomes above and beyond socioeconomic status (e.g. Sammons et al., 2014; Sammons et al., 2015b) - a rare finding in studies of child development and educational progress. Ideally, the THLE would also be able to show such long-term predictive power-even if indirectly through 
first predicting the PHLE. However, for this to be investigated the THLE needs to be included in a future prospective longitudinal study, ideally alongside the PHLE. The inclusion of the eight THLE items in future research could be valuable given that the PHLE has already been included in many post-EPPSE studies (e.g. the Millennium Cohort Study [MCS] and the Study of Early Education and Development [SEED], and the BiKS study in Germany).

Second, future research into the effects of home learning environments on children's development and learning would benefit from a critical reflection upon the common practice of creating HLE scales via summation or averaging of HLE items, particularly as these approaches oblige HLE items to make equal contributions to an HLE scale. Alternative approaches to combining items into a scale avoid this forced equal contribution from items and this can result in a scale with greater predictive power (e.g. Hall et al., 2010). There are a wide range of statistical factor analysis techniques that can be used for this purpose (examples of which can be found used in HLE papers; e.g. Linberg et al., 2020) and these techniques are continually developing (e.g. 'Exploratory Structural Equation Modeling'; see Marsh et al., 2010). Thus, a systematic examination of the impacts of using these alternative approaches in the construction of HLE scales has the potential to improve their reliability and validity. In turn, improved HLE scales have the potential to offer fresh insights into child development and the predictors of child development.

Third, the THLE --although subject to limitations -- shows merit as tool for use in developing a fuller understanding of the environments within which toddlers learn, grow, and live. As such, the THLE can serve as a useful tool for those working with vulnerable families-particularly for researchers and practitioners whose work is concerned with children's development and with adult-child interactions. We also believe that the THLE will be particularly useful for those who work within or alongside early interventions such as Sure Start Children's Centers and its international equivalents (e.g. Head Start in the United States of America; Dream Start in South Korea, and Family Centers in Germany; see respectively: Welshman, 2010; Lee et al., 2015; Stöbe-Blossey et al., 2009). However, the use of the THLE outside of the cultural context in which it was developed (England) prompts the need for more research to investigate the potential need for localization and adaption.

Fourth, for policy makers in the early years, the extension of the well-known PHLE scale down to the toddler years provides new opportunities to evaluate early years practice (across education, health and social policy) against criteria of demonstrable efficacy, effectiveness, and cost-effectiveness (e.g. Heckman, 2006). For example, to show that Sure Start Children's Centers (as a social policy with variable localized implementation) have the potential to significantly improve the home learning environments of the toddlers whose families use them (see Sammons et al., 2015a; Hall et al., 2019b).

\section{REFERENCES}

Abidin, R. R. (1995). Parenting Stress Index: Professional Manual. 3rd ed. Odessa, FL: Psychological Assessment Resources, Inc.

\section{CONCLUSION}

This paper moves the HLE literature forward with the provision of evidence toward the reliability and validity of a new parental self-report scale of the HLE supporting the development of toddlers. The new THLE scale has the potential to inform research, practice and policy (in the toddler period, preschooler period, and later periods) by prompting an increased understanding of the early drivers of educational attainment and development. However, more research is required, particularly on what (if any) long-term outcomes can be expected from home learning environments in the toddler period, and what the implications are for home learning environments from different forms of smart phone and tablet use with children at this very young age.

\section{DATA AVAILABILITY STATEMENT}

The data analyzed in this study is subject to the following licenses/ restrictions: The ECCE dataset is owned by the United Kingdom Government. Requests to access these datasets should be directed to J.E.Hall@Soton.ac.uk.

\section{ETHICS STATEMENT}

The studies involving human participants were reviewed and approved by the University of Oxford Central University Research Ethics Committee (CUREC). Written informed consent to participate in this study was provided by the participants' legal guardian/next of kin.

\section{AUTHOR CONTRIBUTIONS}

All authors listed have made a substantial, direct, and intellectual contribution to the work and approved it for publication.

\section{FUNDING}

This work was supported by a grant from the United Kingdom Department of Education (grant number EOR/SBU/2008/023).

\section{ACKNOWLEDGMENTS}

Our thanks to Sina Fackler (sina.fackler@lifbi.de) for early analyses in preparation for this paper.

Anders, Y., Grosse, C., Rossbach, H.-G., Ebert, S., and Weinert, S. (2013). Preschool and Primary School Influences on the Development of Children's Early Numeracy Skills between the Ages of 3 and 7 Years in Germany. Sch. Effectiveness Sch. Improvement 24 (2), 195-211. doi:10.1080/ 09243453.2012.749794 
Baker, W., Sammons, P., Siraj-Blatchford, I., Sylva, K., Melhuish, E. C., and Taggart, B. (2014). Aspirations, Education and Inequality in England: Insights from the Effective Provision of Pre-school, Primary and Secondary Education Project. Oxford Rev. Educ. 40 (5), 525-542. doi:10.1080/03054985.2014.953921

Bandalos, D. L. (2021). Item Meaning and Order as Causes of Correlated Residuals in Confirmatory Factor Analysis. Struct. Equation Model. A Multidisciplinary J., 1-11. Online First. doi:10.1080/10705511.2021.1916395

Belsky, J., Melhuish, E., Barnes, J., Leyland, A. H., and Romaniuk, H. (2006). Effects of Sure Start Local Programmes on Children and Families: Early Findings from a Quasi-Experimental, Cross Sectional Study. Bmj 332 (1476), 1476. doi:10.1136/bmj.38853.451748.2F

Bonci, A., Mottram, E., McCoy, E., and Cole, J. (2011). A Research Review: The Importance of Families and the home Environment. London, UK: National Literacy Trust. doi:10.1037/e666502011-001

Bradley, R. H., and Caldwell, B. M. (1995). Caregiving and the Regulation of Child Growth and Development: Describing Proximal Aspects of Caregiving Systems. Dev. Rev. 15 (1), 38-85. doi:10.1006/drev.1995.1002

Bronfenbrenner, U., and Morris, P. A. (2006). "The Bioecological Model of Human Development," in Handbook of Child Psychology: Theoretical Models of Human Development. Editors W. Damon and R. M. Lerner (New York: Wiley), 793-828.

Brophy-Herb, H. E., Bocknek, E. L., Choi, H. H., Senehi, N., and Douglas, S. N. (2018). "Terrific Twos: Promoting Toddlers' Competencies in the Context of Important Relationships," in Building Early Social and Emotional Relationships with Infants and Toddlers: Integrating Research and Practice. Editors A. S Morris and A.C. Williamson (Cham, Switzerland: Springer), 157-181. doi:10.1007/978-3-030-03110-7 7

Bruner, J. (1978). "The Role of Dialogue in Language Acquisition," in The Child's Conception of Language. Editors A. Sinclair, R. J. Jarvella, and W. J. M. Levelt (New York, NY: . Springer-Verlag), 241-256.

Buckner, J. C. (2014). "The Why and the Who of Family Homelessness," in Supporting Families Experiencing Homelessness. Editors M. E. Haskett, S. Perlman, and B. A. Cowan (New York, NY: Springer), 3-21. doi:10.1007/978-1-4614-8718-0_1

Burghardt, L., Linberg, A., Lehrl, S., and Konrad-Ristau, K. (2020). The Relevance of the Early Years home and Institutional Learning Environments for Early Mathematical Competencies. J. Educ. Res. Online 12 (3), 103-125.

Crampton, A., and Hall, J. (2017). Unpacking Socio-Economic Risks for reading and Academic Self-Concept in Primary School: Differential Effects and the Role of the Preschool home Learning Environment. Br. J. Educ. Psychol. 87 (3), 365-382. doi:10.1111/bjep.12154

Cronbach, L. J. (1951). Coefficient Alpha and the Internal Structure of Tests. Psychometrika 16, 297-334. doi:10.1007/BF02310555

Cunningham, A. E., and Stanovich, K. E. (1997). Early reading Acquisition and its Relation to reading Experience and Ability 10 Years Later. Dev. Psychol. 33 (6), 934-945. doi:10.1037/0012-1649.33.6.934

De Bondt, M., Willenberg, I. A., and Bus, A. G. (2020). Do Book Giveaway Programs Promote the Home Literacy Environment and Children's Literacy-Related Behavior and Skills? Rev. Educ. Res. 90 (3), 349-375. doi:10.3102/0034654320922140

de la Rochebrochard, E. (2012). Millennium Cohort Study Data Note 1: The home Learning Environment as Measured at Age 3. London, UK: Centre for Longitudinal Studies, Institute of Education, University of London.

Dearden, L., McIntosh, S., Myck, M., and Vignoles, A. (2002). The Returns to Academic and Vocational Qualifications in Britain. Bull. Econ. Res. 54 (3), 249-274. doi:10.1111/1467-8586.00152

Dearden, L., Sibieta, L., and Sylva, K. (2011). "The Socio-Economic Gradient in Early Child Outcomes: Evidence from the Millennium Cohort Study (No. 11, 03)," in IFS working papers (London, UK: Institute for Fiscal Studies).

DeMars, C. (2010). Item Response Theory. Understanding Statistics Measurement. Oxford, UK: Oxford University Press. doi:10.1093/acprof:oso/ 9780195377033.001.0001

Dinkel, D., and Snyder, K. (2020). Exploring Gender Differences in Infant Motor Development Related to Parent's Promotion of Play. Infant Behav. Dev. 59, 101440. doi:10.1016/j.infbeh.2020.101440

Dodici, B. J., Draper, D. C., and Peterson, C. A. (2003). Early Parent-Child Interactions and Early Literacy Development. Top. Early Child. Spec. Educ. 23 (3), 124-136. doi:10.1177/02711214030230030301

Dore, R. A., Logan, J., Lin, T.-J., Purtell, K. M., and Justice, L. M. (2020). Associations between Children's Media Use and Language and Literacy Skills. Front. Psychol. 11, 1734. doi:10.3389/fpsyg.2020.01734
Dunn, T. J., Baguley, T., and Brunsden, V. (2014). From Alpha to omega: A Practical Solution to the Pervasive Problem of Internal Consistency Estimation. Br. J. Psychol. 105 (3), 399-412. doi:10.1111/bjop.12046

Elardo, R., and Bradley, R. H. (1981). The Home Observation for Measurement of the Environment (HOME) Scale: A Review of Research. Dev. Rev. 1 (2), 113-145. doi:10.1016/0273-2297(81)90012-5

Elliot, K., and Sammons, P. (2004). "Exploring the Use of Effect Sizes to Evaluate the Impact of Different Influences on Child Outcomes: Possibilities and Limitations," in But what Does it Mean? The Use of Effect Sizes in Educational Research. Editors I. Schagen and K. Elliott (Slough, UK: NFER), 6-24.

Evangelou, M., Goff, J., Hall, J., Sylva, K., Eisenstadt, N., Paget, C., et al. (2014). Evaluation of Children's Centres in England (ECCE), Strand 3: Parenting Services in Children's Centres. Research Report DFE-RR368. London, UK: Department for Education.

Flouri, E., and Buchanan, A. (2004). Early Father's and Mother's Involvement and Child's Later Educational Outcomes. Br. J. Educ. Psychol. 74 (2), 141-153. doi:10.1348/000709904773839806

Gayle, V., Connelly, R., and Lambert, P. (2015). A Review of Education Measures for Social Research (CPC Working Paper 63). Southampton, UK: ESRC Centre for Population Change.

Goff, J., Hall, J., Sylva, K., Smith, T., Smees, R., Smith, G., et al. (2013). Evaluation of Children's Centres in England (ECCE). Strand 3: Delivery of Family Services by Children's Centres. Research Report DFE-RR297. London, UK: Department for Education.

Goldberg, D. P., and Williams, P. (1988). A User's Guide to the General Health Questionnaire. Windsor: NFER-Nelson.

Granott, N. (2005). Scaffolding Dynamically toward Change: Previous and New Perspectives. New Ideas Psychol. 23 (3), 140-151. doi:10.1016/ j.newideapsych.2006.07.002

Guttman, L. (1945). A Basis for Analyzing Test-Retest Reliability. Psychometrika 10, 255-282. doi:10.1007/BF02288892

Hall, J. E., Sammons, P., Sylva, K., Melhuish, E., Taggart, B., Siraj-Blatchford, I., et al. (2010). Measuring the Combined Risk to Young Children's Cognitive Development: An Alternative to Cumulative Indices. Br. J Devel Psychol. 28, 219-238. doi:10.1348/026151008X399925

Hall, J., Khalil, L., Kelly, A., and Galbraith, D. (2019a). An Upstream Evaluation of the Prototype Coaching E-Books that Will Form Part of Oxford Reading Buddy: Findings from a Mixed Methods Randomized Control Trial. Oxford, UK: Oxford University Press.

Hall, J., Sammons, P., Smees, R., Sylva, K., Evangelou, M., Goff, J., et al. (2019b). Relationships between Families' Use of Sure Start Children's Centres, Changes in home Learning Environments, and Preschool Behavioural Disorders. Oxford Rev. Educ. 45 (3), 367-389. doi:10.1080/03054985.2018.1551195

Hayes, N., and Berthelsen, D. C. (2020). Longitudinal Profiles of Shared Book reading in Early Childhood and Children's Academic Achievement in Year 3 of School. Sch. Eff. Sch. Improv. 31 (1), 31-49. doi:10.1080/09243453.2019.1618347

Heckman, J. J. (2006). Skill Formation and the Economics of Investing in Disadvantaged Children. Science 312, 1900-1902. doi:10.1126/science.1128898

Hox, J. (2010). Multilevel Analysis: Techniques and Applications. 2nd ed. New York, NY: Routledge. doi:10.4324/9780203852279

IBM Corporation (2016). SPSS for Windows (Version 24). Armonk, NY: . IBM Corporation, 2016 . [Computer software]

JASP Team (2019). JASP (Version 0.10.2) [Computer software]. Available at: https://jasp-stats.org.

Jeynes, W. H. (2005). A Meta-Analysis of the Relation of Parental Involvement to Urban Elementary School Student Academic Achievement. Urban Educ. 40 (3), 237-269. doi:10.1177/0042085905274540

Lee, K., and Xie, X. (2017). Associations between home Learning Environment and Mental Health for Young Children Living in China. Soc. Work Ment. Health 16, 284-302. doi:10.1080/15332985.2017.1385566

Lee, Y. J., Bahn, G. H., Lee, S. I., Kim, B., Bhang, S.-Y., Sohn, S. H., et al. (2015). The Early Childhood Care and Education Policy in the United Kingdom and Similar Policies in Korea : A Comparison of the Sure Start Children's Centres and Dream Start. J. Korean Acad. Child Adolesc. Psychiatry 26 (1), 12-21. doi:10.5765/jkacap.2015.26.1.12

Lehrl, S., Evangelou, M., and Sammons, P. (2020). The home Learning Environment and its Role in Shaping Children's Educational Development. Sch. Eff. Sch. Improv. 31 (1), 1-6. doi:10.1080/09243453.2020.1693487 
Lester, S. (2018). Sequential Schooling or Lifelong Learning? International Frameworks through the Lens of English Higher Professional and Vocational Education. Educ. Training 60 (2), 213-224. doi:10.1108/ET-05-2017-0066

Linberg, A., Lehrl, S., and Weinert, S. (2020). The Early Years Home Learning Environment - Associations with Parent-Child-Course Attendance and Children's Vocabulary at Age 3. Front. Psychol. 11 (1425). doi:10.3389/fpsyg.2020.01425

Lovas, G. S. (2011). Gender and Patterns of Language Development in MotherToddler and Father-Toddler Dyads. First Lang. 31 (1), 83-108. doi:10.1177/ 0142723709359241

Maisey, R., Poole, E., Chanfreau, J., and Fry, A. (2015). Evaluation of Children's Centres in England (ECCE): Strand 2: Longitudinal Survey of Families Using Children's Centres in the Most Disadvantaged Areas. Research Report DFERR434. London, UK: Department for Education.

Maisey, R., Speight, S., Haywood, S., Hall, J., Sammons, P., Hussey, D., et al. (2013). Evaluation of Children's Centres in England (ECCE), Strand 2: Baseline Survey of Families Using Children's Centres in the Most Disadvantaged Areas. Research Report DFE-RR260. London, UK: Department for Education.

Marsh, H. W., Lüdtke, O., Muthén, B., Asparouhov, T., Morin, A. J. S., Trautwein, U., et al. (2010). A New Look at the Big Five Factor Structure through Exploratory Structural Equation Modeling. Psychol. Assess. 22 (3), 471-491. doi:10.1037/a0019227

McDonald, R. P. (1999). Test Theory: A Unified Treatment. Mahwah, NJ: Lawrence Erlbaum Associates. doi:10.1111/j.2044-8317.1981.tb00621.x

Melhuish, E. C., Phan, M. B., Sylva, K., Sammons, P., Siraj-Blatchford, I., and Taggart, B. (2008). Effects of the home Learning Environment and Preschool center Experience upon Literacy and Numeracy Development in Early Primary School. J. Soc. Issues 64 (1), 95-114. doi:10.1111/j.1540-4560.2008.00550.x

Melhuish, E., Gardiner, J., and Morris, S. (2017). Study of Early Education and Development (SEED): Impact Study on Early Education Use and Child Outcomes up to Age Three. Research Report DFE-Rr706. London, UK: Department for Education.

Muthén, L. K., and Muthén, B. O. (2015). Mplus (Version 7.4). Los Angeles, CA: . Muthén \& Muthén, 2015 . [Computer software]

Niklas, F., and Schneider, W. (2017). Home Learning Environment and Development of Child Competencies from Kindergarten until the End of Elementary School. Contemp. Educ. Psychol. 49, 263-274. doi:10.1016/ j.cedpsych.2017.03.006

Niklas, F., Wirth, A., Guffler, S., Drescher, N., and Ehmig, S. C. (2020). The Home Literacy Environment as a Mediator between Parental Attitudes toward Shared Reading and Children's Linguistic Competencies. Front. Psychol. 11 (21), 1628. doi:10.3389/fpsyg.2020.01628

Nunnally, B. H., and Bernstein, J. C. (1994). Psychometric Theory. 3rd ed.. London, UK: McGraw-Hill.

Peacock-Chambers, E., Martin, J. T., Necastro, K. A., Cabral, H. J., and BairMerritt, M. (2017). The Influence of Parental Self-Efficacy and Perceived Control on the home Learning Environment of Young Children. Acad. Pediatr. 17 (2), 176-183. doi:10.1016/j.acap.2016.10.010

Posner, M. I., Rothbart, M. K., Sheese, B. E., and Voelker, P. (2014). Developing Attention: Behavioral and Brain Mechanisms. Adv. Neurosci. 2014, 1-9. doi:10.1155/2014/405094

Ramey, C. T., and Ramey, S. L. (2004). Early Learning and School Readiness: Can Early Intervention Make a Difference? Merrill-Palmer Q. 50, 471-491. doi:10.1353/mpq.2004.0034

Rigdon, E. E. (1996). CFI versus RMSEA: A Comparison of Two Fit Indexes for Structural Equation Modeling. Struct. Equation Model. A Multidiscip. J. 3 (4), 369-379. doi:10.1080/10705519609540052

Rodriguez, E. T., and Tamis-LeMonda, C. S. (2011). Trajectories of the Home Learning Environment across the First 5 years: Associations with Children's Vocabulary and Literacy Skills at Prekindergarten. Child. Dev. 82 (4), 1058-1075. doi:10.1111/j.1467-8624.2011.01614.x

Romeo, R. R., Leonard, J. A., Robinson, S. T., West, M. R., Mackey, A. P., Rowe, M. L., et al. (2018). Beyond the 30-Million-word Gap: Children's Conversational Exposure Is Associated with Language-Related Brain Function. Psychol. Sci. 29 (5), 700-710. doi:10.1177/0956797617742725

Sammons, P., and Anders, Y. (2015). "Researching Equity and Effectiveness in Education: Examples from the UK and Germany, Chapter 7.5 Pp. 1289-1320," in International Handbook Of Interpretation In Educational Research, Part 2. Editors P. Smeyers, D. Bridges, N. Burbles, and M. Griffiths (Dordrecht: Springer International Handbooks of Education Springer).
Sammons, P., Elliot, K., Sylva, K., Melhuish, E., Siraj-Blatchford, I., and Taggart, B. (2004). The Impact of Pre-school on Young Children's Cognitive Attainments at Entry to Reception. Br. Educ. Res. J. 30 (5), 691-712. doi:10.1080/0141192042000234656

Sammons, P., Hall, J., Smees, R., Goff, J., Sylva, K., Smith, T., et al. (2015a). Evaluation of Children's Centres in England (ECCE). Strand 4: The Impact of Children's Centres: Studying the Effects of Children's Centres in Promoting Better Outcomes for Young Children and Their Families. Research Report DFE-RR495. London, UK: Department for Education.

Sammons, P., Sylva, K., Melhuish, E., Siraj, I., Taggart, B., Smees, R., et al. (2014). Influences on Students' Dispositions and Well-Being in Key Stage 4 at Age 16. London, UK: Institute for Education/Department for Education.

Sammons, P., Toth, K., Sylva, K., Melhuish, E., Siraj, I., and Taggart, B. (2015b). The Long-Term Role of the home Learning Environment in Shaping Students' Academic Attainment in Secondary School. J. Children's Serv. 10 (3), 189-201. doi:10.1108/JCS-02-2015-0007

Shuey, E., and Kankaras, M. (2018). The Power and Promise of Early Learning, OECD Working Paper. Paris, France: OECD Publishing.

Sijtsma, K. (2009). On the Use, the Misuse, and the Very Limited Usefulness of Cronbach's Alpha. Psychometrika 74 (1), 107-120. doi:10.1007/s11336-008-9101-0

Silinskas, G., Torppa, M., Lerkkanen, M.-K., and Nurmi, J.-E. (2020). The home Literacy Model in a Highly Transparent Orthography. Sch. Eff. Sch. Improv. 31 (1), 80-101. doi:10.1080/09243453.2019.1642213

Son, S.-H., and Morrison, F. J. (2010). The Nature and Impact of Changes in home Learning Environment on Development of Language and Academic Skills in Preschool Children. Dev. Psychol. 46 (5), 1103-1118. doi:10.1037/a0020065

Stöbe-Blossey, S., Mierau, S., and Tietze, W. (2009). "Von der Kindertageseinrichtung zum Familienzentrum - Konzeption, Entwicklungen und Erprobung des Gütesiegels 'Familienzentrum NRW' [From the children's day-care centre to the family centre - Conception, development and testing of the seal of quality 'Family Centre NRW']," in Frühpädagogische Förderung in Institutionen: Zeitschrift für Erziehungswissenschaft [Early education in institutions: Journal of educational science. Editors H. G. Roßbach and H. P. Blossfeld (Wiesbaden: VS Verlag für Sozialwissenschaften), 105-122.

Sylva, K., Goff, J., Hall, J., Eisenstadt, N., Smith, T., Evangelou, M., et al. (2015). Evaluation of Children's Centres in England (ECCE). Strand 3: The Organisation, Services and Reach of Children's Centres in England. Research Report DFE-Rr433. London, UK: Department for Education.

Sylva, K., Melhuish, E., Sammons, P., Siraj-Blatchford, I., and Taggart, B. (2010). Early Childhood Matters: Evidence from the Effective Pre-school and Primary Education Project. Abingdon, UK: Routledge.

Tanner, E., Agur, M., Hussey, D., and Hall, J. (2012). Evaluation of Children's Centres in England (ECCE). Strand 1: First Survey of Children's Centre Leaders in the Most Deprived Areas. Research Report DFE-RR230. London, UK: Department for Education.

Toth, K., Sammons, P., Sylva, K., Melhuish, E., Siraj, I., and Taggart, B. (2020). Home Learning Environment across Time: the Role of Early Years HLE and Background in Predicting HLE at Later Ages. Sch. Eff. Sch. Improv. 31 (1), 7-30. doi:10.1080/09243453.2019.1618348

Vygotsky, L. S. (1978). Mind in Society: The Development of Higher Psychological Processes. Cambridge, MA: Harvard University.

Weitzman, B. C. (1989). Pregnancy and Childbirth: Risk Factors for Homelessness? Fam. Plann. Perspect. 21 (4), 175-178. doi:10.2307/2135809

Welshman, J. (2010). From Head Start to Sure Start: Reflections on Policy Transfer. Child. Soc. 24, 89-99. doi:10.1111/j.1099-0860.2008.00201.x

Wirth, A., Ehmig, S. C., Drescher, N., Guffler, S., and Niklas, F. (2020). Facets of the Early Home Literacy Environment and Children's Linguistic and Socioemotional Competencies. Early Educ. Dev. 31 (6), 892-909. doi:10.1080/10409289.2019.1706826

Conflict of Interest: The authors declare that the research was conducted in the absence of any commercial or financial relationships that could be construed as a potential conflict of interest.

Copyright (c) 2021 Hall, Sylva, Sammons, Smees, Evangelou, Smith and Goff. This is an open-access article distributed under the terms of the Creative Commons Attribution License (CC BY). The use, distribution or reproduction in other forums is permitted, provided the original author(s) and the copyright owner(s) are credited and that the original publication in this journal is cited, in accordance with accepted academic practice. No use, distribution or reproduction is permitted which does not comply with these terms. 